\title{
Proteinograma de vacas leiteiras positivas para fasciolose
}

Sayanne Luns Hatum, Natânia do Carmo Sperandio, Isabella Vilhena Freire Martins, Dirlei Molinari Donatele, Graziela Barioni", Aline Nunes Simões, Áquila Flávia da Rocha Braga, Isabelle Pereira de Lacerda, Matheus Cruz de Oliveira, Felippe Bizarro Silva

Centro de Ciências Agrárias e Engenharias, Universidade Federal do Espírito Santo (UFES), Vitória, ES, Brasil

*Autor correspondente

e-mail: grazibari@gmail.com

\section{Resumo}

A fasciolose, enfermidade de grande importância na Medicina Veterinária por ser responsável por perdas econômicas, resulta do acometimento do órgão parasitado, o fígado e as vias biliares. A região sul do estado do Espírito Santo é considerada endêmica para Fasciola hepatica, devido às condições climáticas adequadas para o desenvolvimento do molusco do gênero Lyminaea, que atua como hospedeiro intermediário, possibilitando assim um ciclo biológico completo. 0 acometimento do fígado, causado pela migração do parasita, compromete o seu desempenho na função de metabolização, produção de proteínas séricas, proteínas de fase aguda (PFA) e células com importante atuação imunológica. Diante disso, o presente estudo tem como objetivo avaliar a função hepática dessas vacas leiteiras com Fasciolose, e para isso, criou-se um proteinograma, no qual foram mensuradas as proteínas totais (PT), a albumina (ALB) e as globulinas (GLO), juntamente com a função hepática, analisando as enzimas aspartato aminotransferase (AST), a fosfatase alcalina (FA) e a gama-glutamiltransferase (GGT). A mensuração da PT e FA foi realizada de acordo com as recomendações dos kits comerciais Bioclin ${ }^{\circledR}$, da ALB e AST, seguindo as recomendações dos kits comercias Labtest ${ }^{\circledR}$ e do GGT, seguindo-se as recomendações do kit comercial BioSystems ${ }^{\circledR}$. Para a determinação da concentração da globulina subtraiu-se a concentração de albumina, do teor total de proteína. 0 preoteinograma foi desempenhado por meio de eletroforese em gel de poliacrilamida com duodecil sulfato de sódio (SDS-PAGE). Os exames foram realizados através da coleta de sangue de 142 vacas mestiças de aptidão leiteira em diferentes fases de lactação, provenientes de dez fazendas do município. Para o diagnóstico da Fasciolose, foi realizado o ensaio imunoenzimático (ELISA), detectando anticorpos direcionados contra a F. hepatica, utilizando-se o kit IDEXX Fasciolosis Verification ${ }^{\circledR}$, seguindose as recomendações do fabricante. 0 município de Jerônimo Monteiro obteve prevalência de 50,7\% para 
a Fasciolose. Não houve diferença significativa nas médias e desvios padrão das enzimas hepáticas e as variáveis do perfil protéico entre animais sadios e animais positivos para Fasciolose.

Apoio Financeiro: Fundação de Amparo à Pesquisa e Inovação do Espírito Santo (FAPES). 